\title{
Combined hysteroscopy and laparoscopy in evaluation of female infertility
}

\author{
Nikita Gandotra ${ }^{1 *}$, Syed Masuma Rizvi², Preeti Sharma ${ }^{3}$
}

\begin{abstract}
${ }^{1}$ Department of Obstetrics and Gynecology, Government Medical College, Jammu, Jammu and Kashmir, India ${ }^{2}$ Department of Obstetrics and Gynecology, Government Medical College, Srinagar, Jammu and Kashmir, India ${ }^{3}$ Department of Obstetrics and Gynecology, RPGMC, Tanda, Himachal Pradesh, India
\end{abstract}

Received: 12 November 2018

Accepted: 06 December 2018

\author{
*Correspondence: \\ Dr. Nikita Gandotra, \\ E-mail: nikigandotra@gmail.com
}

Copyright: $($ ) the author(s), publisher and licensee Medip Academy. This is an open-access article distributed under the terms of the Creative Commons Attribution Non-Commercial License, which permits unrestricted non-commercial use, distribution, and reproduction in any medium, provided the original work is properly cited.

\begin{abstract}
Background: Infertility has always been one of the most elusive symptom complexes that perplex the best gynecologists and affects about $10-15 \%$ of reproductive age couples.

Methods: This descriptive study was conducted in the Postgraduate Department of Obstetrics and Gynaecology at Government Medical College, Jammu for a period of 18 months in which 100 infertile females attending OPD for infertility workup were subjected to detailed relevant history taking followed by physical examination. Diagnostic hysteroscopy and laparoscopy along with laparoscopic chromopertubation was carried out after written informed consent including minimal therapeutic interventions if required.

Results: Out of 100 patients included in the study, $67(67 \%)$ presented with primary infertility and 33 (33\%) presented with secondary infertility. Combined laparoscopy and hysteroscopy was normal in $13 \%$ (13) of cases. Out of 100 patients, abnormal laparoscopic findings were noted in $73 \%$ of patients: Endometriosis ( $13 \%)$,Polycystic ovaries (12\%), Unilateral tubal block (11\%), Pelvic inflammatory disease (9\%).Abnormal hysteroscopic findings were noted in $47 \%$ of patients: Submucous myoma (8\%), unilateral ostial block (8\%),Endometrial polyp (7\%), Hyperplasic endometrium (7\%), Cervical stenois (6\%).Most common cause of infertility in present study on Combined hysteroscopy and laparoscopy was Endometriosis (13\%) followed by Polycystic ovaries (12\%),Uterine myoma (12\%) out of which 5\% myomas were diagnosed on laparoscopy and $8 \%$ on hysteroscopy and $1 \%$ had myoma diagnosed on both hysteroscopy and laparoscopy. In the primary infertility group most, common finding was Polycystic ovaries (16.4\%) followed by Endometriosis $(14.9 \%)$ and uterine myoma (14.9\%) while in patients suffering from secondary infertility, most patients had Bilateral tubal block (18.2\%), Pelvic inflammatory disease (12.1\%), Unilateral tubal block (12.1\%), intrauterine adhesions (12.1\%).

Conclusions: Combined Hysteroscopy and Laparoscopy is a quintessential tool that provides cost-effective, comprehensive and single set-up diagnostic aid in infertile patients.
\end{abstract}

Keywords: Hysteroscopy, Infertility, Laparoscopy

\section{INTRODUCTION}

Childbearing and raising of children are extremely important events in every human's life and are strongly associated with the ultimate goals of completeness, happiness and family integration. Infertility has always been one of the most elusive symptom complexes that perplex the best gynecologists. It is defined as "inability to achieve a clinical pregnancy after 12 months or more of regular unprotected sexual intercourse." Infertility can be Primary in which no previous pregnancies has occurred and Secondary in which a previous pregnancy, although not a live birth has occurred. ${ }^{2}$ Infertility affects about $10-15 \%$ of reproductive age couples. According to 
a systematic analysis of 277 health surveys, $1.9 \%$ of child bearing age suffered from primary infertility and $10.5 \%$ of child bearing age suffered from secondary infertility. ${ }^{3}$ Various factors for infertility include: Male factor (25$40 \%)$, female factor (40-55\%), both (10\%), Unexplained $(10 \%)$.

Evaluation should be offered to all couples who have failed to conceive after a year or more of regular unprotected intercourse, but a year of infertility is not a prerequisite for evaluation. Earlier evaluation is justified for women with irregular or infrequent menses, history of pelvic infection or endometriosis or having a male partner with known or suspected poor semen quality and also is warranted after 6 months of unsuccessful effort for women over the age of 35 years. ${ }^{4}$

Tubal and peritoneal pathology is among the most common causes of infertility and the primary diagnosis in approximately $30-40 \%$ of both younger and older infertile women. Laparoscopy is the gold standard for diagnosing tubal and peritoneal disease because no other imaging technique provides same degree of sensitivity and specificity.

It is also helpful in diagnosing ovarian and uterine factors. ${ }^{5}$ Laparoscopy provides both a paranomic view of pelvic reproductive anatomy and a magnified view of the uterine, ovarian, tubal and peritoneal surfaces aiding in the diagnosis and treatment of infertility.

One of the basic steps of infertility workup is to evaluate the shape and regularity of the uterine cavity. Infertility related to uterine factor abnormalities has estimated to be etiology in $10-15 \%$ couples seeking treatment. Hysteroscopy permits direct visualization of the cervical canal and uterine cavity, enabling observation of the shape and vascular pattern of any abnormality. In addition, hysteroscopic approach offers the possibility of obtaining endometrial biopsies under visual control. The main advantage of hysteroscopy over hysterosalpingography is its capacity to inspect the uterine cavity.

Filling defects and partial failure of mullerian ducts can be suspected, but not always proven by hysterosalpingopraphy. Hysteroscopy can diagnose much more precisely, compared with HSG and even trasvaginal ultrasonography, small intrauterine lesions that might affect fertility. ${ }^{6}$

The present study thus intends to evaluate female infertility by combined hysteroscopy and laparoscopy in the same sitting.

\section{METHODS}

This study was conducted in the Postgraduate Department of Obstetrics and Gynaecology at Government Medical College Jammu for a period of one and a half year after obtaining ethical clearance from institutional ethical committee. Sample size was 100 infertile females .This was a Descriptive study.

\section{Inclusion criteria}

- Married women of reproductive age group with primary/secondary infertility willing for infertility workup.

- Normal semen analysis of husband.

\section{Exclusion criteria}

- Couples with Male factor infertility.

- Couples who have not lived together for 12 months.

- Patients with absolute/relative contraindications for laparoscopy or hysteroscopy

- Patients not willing for surgery.

All couples attending gynaecology OPD for infertility workup were thoroughly counseled and all the possible causes for their infertility were explained to them. The female partners were subjected to detailed relevant history taking followed by physical examination with special reference to secondary sexual characters, thyroid examination, and breast examination, abdominal examination, per speculum and per vaginal examination. Husband's semen analysis was carried to rule out male factor infertility. All baseline investigations including CBC, blood group, VDRL, HIV, HbsAg, LFT, KFT, blood sugar, serum electrolytes, urine analysis was done in the hospital.

Serum progesterone (mid luteal progesterone on day 21 of 28-day cycle or 1 week before expected period of $>10 \mathrm{ng} / \mathrm{ml}$ ), FSH and LH on day 3 was done. AMH levels were also obtained. Serum Prolactin and thyroid function tests were carried out to rule out hyperprolactinemia and thyroid function abnormalities. Transvaginal sonography was carried out before the procedure. All the selected patients were admitted 2 days prior to surgery in the secretory phase after investigations. Preanaesthethic evaluation was carried out in the evening and preparation of the patient for hysteroscopy and laparoscopy was done. Prophylactic antibiotic was given a night before and at the time of induction. Diagnostic hysteroscopy and laparoscopy along with laparoscopic chromopertubation was carried out along with minimal therapeutic interventions if required, after obtaining written informed consent from the patients. The data was collected on a set proforma and was analyzed to see the frequency of various abnormalities in primary and secondary infertility and role of combined hysteroscopy and laparoscopy was assessed.

\section{Statistical analysis}

Data was entered using Statistical Package for Social Sciences and in Microsoft excel software. Continuous variables were summarized in the form of mean and 
standard deviation. Categorical variables were summarized as percentage. Frequency distribution tables, bar charts and pie charts were used for data presentation.

\section{RESULTS}

Out of 100 patients included in the study, $67(67 \%)$ presented with primary infertility and $33(33 \%)$ presented with secondary infertility (Table 1).

Table 1: Distribution of patients according to the type of infertility.

\begin{tabular}{|l|l|l|}
\hline Type of Infertility & No. & $\%$ \\
\hline Primary & 67 & 67 \\
\hline Secondary & 33 & 33 \\
\hline Total & 100 & 100 \\
\hline
\end{tabular}

Mean age at presentation for primary infertility was $28.6 \pm 4.20$ years and for secondary infertility it was $32.1 \pm 3.84$ years. Mean duration of infertility in the patients of primary and secondary infertility was $3.4 \pm 1.82$ years and $4.8 \pm 2.26$ years respectively (Table 2 ).

Table 2: Age distribution of infertile patients.

\begin{tabular}{|l|l|l|l|l|l|l|}
\hline \multirow{2}{*}{ Age } & \multicolumn{2}{|l|}{ Primary } & \multicolumn{2}{l|}{ Secondary } & \multicolumn{2}{l|}{ Total } \\
\hline $20-25$ & No. & $\%$ & No. & $\%$ & No. & $\%$ \\
\hline $25-30$ & 33 & 11.9 & 2 & 6.1 & 10 & 10 \\
\hline $30-35$ & 18 & 26.9 & 16 & 48.5 & 34 & 34 \\
\hline$\geq 35$ & 8 & 11.9 & 10 & 30.3 & 18 & 18 \\
\hline Total & 67 & 100 & 33 & 100 & 100 & 100 \\
\hline Mean+SD & $28.6 \pm 4.20$ & $32.1 \pm 3.84$ & $\begin{array}{l}\text { P-value } \\
<0.001 *\end{array}$ \\
\hline
\end{tabular}

*Statistically Significant Difference $(\mathrm{P}$-value $<0.05)$

Most common menstrual abnormality in the infertile patients was menorrhagia (11\%) followed by oligomenorrhea (9\%) and dysmenorrhea (9\%). In the primary group, most common abnormality was menorrhagia $(11.9 \%)$ and least was polymenorrhagia $(1.5 \%)$ and polymenorrhea $(1.5 \%)$. In the secondary group, maximum patients had menorrhagia (9.1\%) and dysmenorrhea $(9.1 \%)$.

Combined laparoscopy and hysteroscopy was performed on 100 infertile patients and various causes of infertility were tabulated. Combined laparoscopy and hysteroscopy was normal in $13 \%$ (13) patients, out of which 7 patients $(10.4 \%)$ belonged to primary infertility group and 6 patients $(18.2 \%)$ belonged to secondary infertility group. Abnormal laparoscopic findings were noted in $73 \%$ patients and abnormal hysteroscopic findings were noted in $47 \%$ patients.

Combined laparoscopy and hysteroscopy was abnormal in $33(33 \%)$ patients out of whom, 23 patients $(34.3 \%)$ were from primary infertility group and 10 patients $(30.3 \%)$ were form secondary infertility group (Figure 1$)$.
Uterine cavity was examined by hysteroscopy in all the patients.

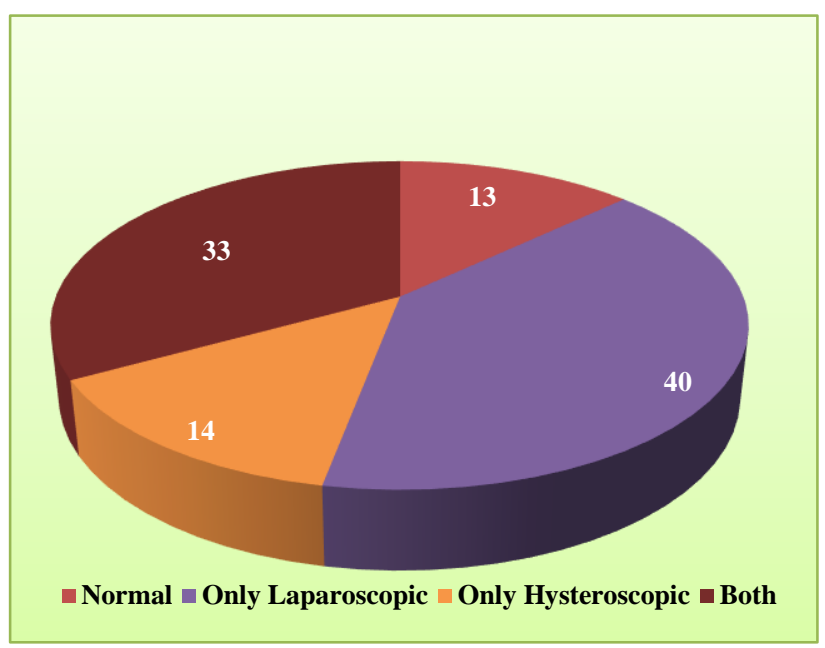

Figure 1: Combined hysteroscopic and laparoscopic findings in infertile patients.

Most common abnormality found in the uterine cavity was uterine myoma found in $8 \%$ patients (Table 3). Intrauterine adhesions (Asherman Syndrome) were found in $4 \%$ patients, all belonging to secondary infertility group.

In the primary infertility group, endometrial polyp was found in $7.5 \%$ patients (5) and uterine septum in $3 \%$ (2) patients.

Table 3: Hysteroscopic findings of infertile patients.

\begin{tabular}{|l|l|l|l|l|}
\hline & $\begin{array}{l}\text { Primary } \\
\text { infertility }\end{array}$ & $\begin{array}{l}\text { Secondary } \\
\text { infertility }\end{array}$ & \multicolumn{2}{l|}{ Total } \\
\hline No. & No. & No. & $\%$ \\
\hline $\begin{array}{l}\text { Endocervical } \\
\text { canal }\end{array}$ & 6 & 4 & 10 & 10 \\
\hline Uterine cavity & 15 & 8 & 23 & 23 \\
\hline Endometrium & 8 & 0 & 8 & 8 \\
\hline Ostia & 8 & 4 & 12 & 12 \\
\hline Total & 37 & 16 & 53 & 53 \\
\hline
\end{tabular}

In patients of secondary infertility, endometrial polyp and uterine septum was found in $6.1 \%$ (2) patients each. On laparoscopy, tuboperitonal abnormlities were most common (Figure2). Endometriosis observed in $13 \%$ patients followed by unilateral tubal block in $11 \%$ patients, pelvic inflammatory disease in $9 \%$ patients and unilateral tubal block in $7 \%$ patients.

In ovarian factors, most common abnormality noted was polycystic ovaries in $12 \%$ patients followed by chocolate cyst in $7 \%$ patients. $5 \%$ patients had uterine abnormalities on laparoscopy and all of them had uterine myoma, $3 \%$ in primary infertility group and $9.1 \%$ in secondary infertility group (Table 4 and 5). On combined hysteroscopy and laparoscopy, most common cause of infertility in present 
study was endometriosis in $13 \%$ patients followed by polycystic ovaries in $12 \%$ patients.

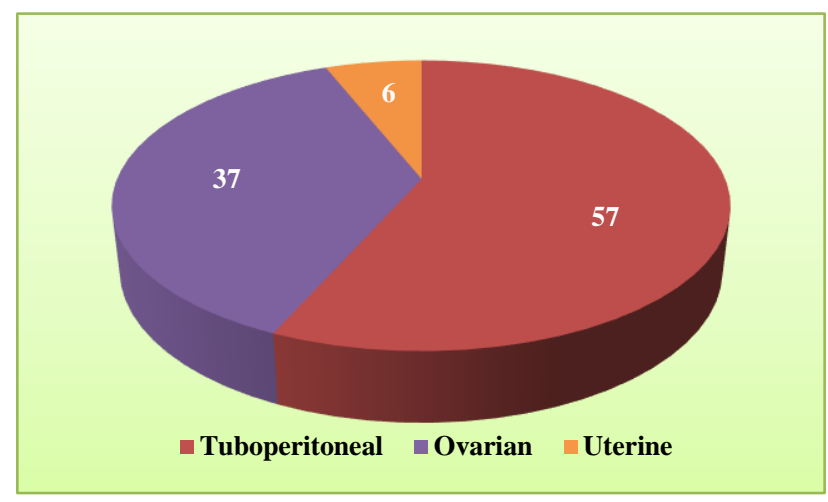

Figure 2: Causes of infertility on laparoscopy.
$12 \%$ patients had uterine myoma out of which, 5\% myomas were diagnosed on laparoscopy, $8 \%$ on hysteroscopy and $1 \%$ patient had myoma diagnosed on both hysteroscopy and laparoscopy.

$11 \%$ patients had unilateral tubal block on laparoscopy, 9\% patients had pelvic inflammatory disease, $8 \%$ patients had unilateral ostial block. $7 \%$ patients had chocolate cyst, $7 \%$ patients had bilateral tubal clock and $7 \%$ patients had endometrial polyp. In the primary infertility group, most common abnormality observed was polycystic ovaries $(16.4 \%)$ followed by endometriosis $(14.9 \%)$ and uterine myoma $(14.9 \%)$. In the patients suffering from secondary infertility, most patients had bilateral tubal block (18.2\%) followed by PID (12.1\%), unilateral tubal block $(12.1 \%)$, intrauterine adhesions $(12.1 \%)$.

Table 4: Tuboperitoneal factors in infertile patients on laparoscopy.

\begin{tabular}{|c|c|c|c|c|c|c|c|}
\hline \multirow[t]{2}{*}{ Factors } & \multicolumn{2}{|c|}{$\begin{array}{l}\text { Primary } \\
\text { infertility }\end{array}$} & \multicolumn{2}{|c|}{$\begin{array}{l}\text { Secondary } \\
\text { infertility }\end{array}$} & \multicolumn{2}{|c|}{ Total } & \multirow[t]{2}{*}{ P-value } \\
\hline & No. & $\%$ & No. & $\%$ & No. & $\%$ & \\
\hline Unilateral tubal block & 7 & 10.4 & 4 & 12.1 & 11 & 11 & \multirow{8}{*}{$0.289 *$} \\
\hline Bilateral tubal block & 1 & 1.5 & 6 & 18.2 & 7 & 7 & \\
\hline Bilateral tubal block with beaded appearance (TB) & 3 & 4.5 & 1 & 3.0 & 4 & 4 & \\
\hline Fimbrial cyst & 2 & 3.0 & 0 & 0.0 & 2 & 2 & \\
\hline Congenital anomaly & 1 & 1.5 & 0 & 0.0 & 1 & 1 & \\
\hline Endometriosis & 10 & 14.9 & 3 & 9.1 & 13 & 13 & \\
\hline PID & 5 & 7.5 & 4 & 12.1 & 9 & 9 & \\
\hline Total & 29 & 43 & 18 & 55 & 47 & 47 & \\
\hline
\end{tabular}

$\mathrm{TB}=$ Tuberculosis; $\mathrm{PID}=$ Pelvic inflammatory disease *Statistically Non-significant Difference (P-value $>0.05$

Table 5: Ovarian factors in infertile patients on laparoscopy.

\begin{tabular}{|c|c|c|c|c|c|c|c|}
\hline \multirow{2}{*}{ Ovarian } & \multicolumn{2}{|c|}{ Primary infertility } & \multicolumn{2}{|c|}{ Secondary infertility } & \multicolumn{2}{|c|}{ Total } & \multirow{2}{*}{ P-valuc } \\
\hline & No. & $\%$ & No. & $\%$ & No. & $\%$ & \\
\hline Simple cyst & 4 & 6.0 & 1 & 3.0 & 5 & 5 & \multirow{6}{*}{$0.023 *$} \\
\hline Polycystic ovaries & 11 & 16.4 & 1 & 3.0 & 12 & 12 & \\
\hline Chocolate cyst & 5 & 7.5 & 2 & 6.1 & 7 & 7 & \\
\hline Bald ovaries & 4 & 6.0 & 2 & 6.1 & 6 & 6 & \\
\hline LUF & 1 & 1.5 & 0 & 0.0 & 1 & 1 & \\
\hline Total & 25 & 37 & 6 & 18 & 31 & 31 & \\
\hline
\end{tabular}

LUF=Luteinized Unruptured follicle*Statistically Significant Difference $(\mathrm{P}$-value $<0.05)$

Endometrial biopsy was taken following hysteroscopy and laparoscopy and histopathological evaluation was done. $71 \%$ patients had secretory endometrium in the report followed by proliferative endometrium in $15 \%$ patients, endometrial hyperplasia in $6 \%$ patients and endometrial atrophy in $4 \%$ patients. Chronic granulomatous inflammation with Giant cells was noted in 4 patients (TB). Proliferative endometrium was found in $19.4 \%$ patients with primary infertility who had anovulation and $6.1 \%$ patients with secondary infertility.

\section{DISCUSSION}

In the present study, out of 100 infertile patients, $67 \%$ (67) presented with primary infertility and 33\% (33) presented with secondary infertility. It was comparable with studies conducted by Nayak KP et al, Shetty KS et al, Vaid K et al and Shah JS et al. ${ }^{7-11}$ Present study revealed abnormal laparoscopic findings in $73 \%$ patients and abnormal hysteroscopic findings in $47 \%$ patients. 
Forty\% (40) patients had abnormal findings on laparoscopy alone and $14(14 \%)$ patients had abnormal findings on hysteroscopy alone which was similar to the study conducted by Singh $\mathrm{R}$ et al. ${ }^{9}$ Mean age of patients with primary infertility was $28.6 \pm 4.20$ years and with secondary infertility was $32.1 \pm 3.84$ years $(34 \%)$ that was comparable to the studies conducted by Shetty KS et al,

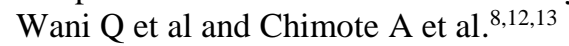

In present study, uterine myoma was the most common abnormality found on hysteroscopy similar to Shah JS et al $(8 \%)$, depicting that myomas influence infertility. $40 \%$ patients had only abnormal laparoscopic findings while $33 \%$ of patients had abnormalities on both hysteroscopy and laparoscopy resulting in total of abnormal findings in $73 \%$ patients. $10 \%$ patients had abnormal findings in more than one parameter on laparoscopy. ${ }^{11}$

In present study, tuboperitoneal factors were found as leading cause for infertility on laparoscopy in $47 \%$ patients followed by ovarian factors $(31 \%)$ and uterine factors (5\%). Similar results were seen in the study conducted by Shah JS et al who found tuboperitoneal factor in $38 \%$ and ovarian factor in $31 \%$ of the patients on laparoscopy.

Most common tuboperitoneal finding was endometriosis observed in $13 \%$ patients. ${ }^{11}$ The golden rule in suspected patients with endometriosis is visual confirmation through laparoscopy (as mild endometriosis can only be detected on laparoscopy) before labeling a patient with endometriosis and starting treatment.

In present study, 5\% patients had uterine abnormalities on laparoscopy and all of them had uterine myoma, $3 \%$ in primary infertility group and $9.1 \%$ in secondary infertility group. It correlated with the study conducted by Shah JS et al in which, uterine factors on laparoscopy was found in $4 \%$ patients. $^{11}$

Summing up, most common abnormality found on laparoscopy was tuboperitoneal (47\%) followed by ovarian $(31 \%)$ and uterine $(5 \%)$. Most patients had endometriosis (13\%) followed by polycystic ovaries $(12 \%)$, unilateral tubal block $(11 \%)$, pelvic inflammatory disease (9\%). Acid fast bacilli (AFB) culture was sent for all patients in present study. Out of 4 suspected patients of tuberculosis on laparoscopy, AFB culture was positive in 2 patients (2\%) and in rest of the patients (98\%), AFB culture was negative.

Genital tuberculosis is an important cause of female infertility in developing countries like India. It is one of the major causes for severe tubal disease leading to infertility. Unlike pulmonary tuberculosis, diagnosis of genital tuberculosis is difficult because in majority of cases the disease is either asymptomatic or has varied clinical presentation. ${ }^{14}$ Similar results were seen in studies conducted by Vaid K et al and Shah JS et al. ${ }^{10,11}$

\section{CONCLUSION}

Diagnostic hysterolaparoscopy is an effective and safe tool in comprehensive evaluation of female infertility, particularly for detecting peritoneal endometriosis, ovarian pathologies, adnexal adhesions and abnormalities in the uterus. These correctable abnormalities are unfortunately missed by routine pelvic examination and usual imaging procedures. It is a very useful tool that can detect various structural abnormalities in multiple pelvic sites like tubes, ovaries and uterus in the same sitting.

Funding: No funding sources

Conflict of interest: None declared

Ethical approval: The study was approved by the Institutional Ethics Committee

\section{REFERENCES}

1. WHO-ICMART revised glossary. Fertility and Sterility and Human Reproduction 2009

2. Richard O. Burney, Daniel J. Schust Mylene W.M. Yao INFERTILITY Chapter 30: BEREK and Novak's Gynaecology 14th ed.

3. National, Regional, Global trends in Infertility Prevalence since 1990 WHO study: A systematic study of 277 health surveys: 2012.

4. Marc A. Fritz and Leon Speroff. Female infertility Chapter 27:Clininical Gynecologic Endocrinology and Infertility $8^{\text {th }}$ Edition

5. Parveen S, Khanam M. Role of combined diagnostic laparoscopy and simultaneous diagnostic hysteroscopy for evaluation of female sub fertility factors. J Surg Pak. 2010;15(1):44-7.

6. Abdelazim IA, Elezz AA. Complimentary roles of hysteroscopy and saline infusion hysterosonography in uterine cavity assessment before in vitro fertilization. Asian Pac J Reprod. 2012;1(1):1316.

7. Nayak KP, Mahapatra CP, Mallick JJ, Swain S, Mitra S, Sahoo J. Role of diagnostic hysterolaparoscopy in the evaluation of infertility: A retrospective study of 300 patients J Hum Reprod Sci.2012;6(1):32-34.

8. Shetty KS, Shetty H, Rai S. Laparoscopic evaluation of tubal factor in cases of infertility. Int J Reprod Contracept Obstet Gynecol.2013;2(3):410-3

9. Singh R, Singh S, Yadav P, Goyal M. Role of diagnostic laparohysteroscopy in the management of infertile females. J Evolution Med Dental Sci. 2013;2(12):1792-8.

10. Vaid K, Mehra S, Verma M, Jain S, Sharma A, Bhaskaran S. Pan Endoscopic approach "Hysterolaparoscopy" as an initial procedure in selected infertile women. J Clinic Diagnos Res. 2014; Vol 8(2):95-8.

11. Shah SJ, Shah AC, Trivedi YN. Study of combined Laparoscopic and Hysteroscopic findings in 100 cases of Infertility. NHL J Med Sci. 2014;3(2).

12. Wani Q, Ara R, Dangroo AS, Beig M. Diagnostic laparoscopy in the evaluation of female factors in 
infertility in Kashmir Valley. Int J Women's Health Reproduct Sci.2014;2(3).

13. Chimote A, Samal S, Hariharan C, Angik R. Laparoscopy and hysteroscopy in patients of infertility in a rural set up. Int $\mathbf{J}$ Reprod Contracept Obstet Gynecol. 2015;4(2):322-8.

14. Mondal SK, Dutta TK. A ten-year clinicopathological study of female genital tuberculosis and impact on fertility. JNMA J Nepal Med Assoc. 2009;48(173)52-7.

Cite this article as: Gandotra N, Rizvi MS, Sharma

P. Combined hysteroscopy and laparoscopy in evaluation of female infertility. Int J Reprod Contracept Obstet Gynecol 2019;8:267-72. 